\title{
The Structure of 'The Structural Design of Shaft'
}

\author{
Zhu Dai-gen, Yang Can-yu, Wang Yuan,Cheng Bin, Deng Ting-ting \\ College of Machinery and Communication, Southwest Forestry University \\ Kunming 650224, China
}

\begin{abstract}
The structural design of shaft" is an important section in the course of Machine design, and occupies a significant position in the theory of teaching and practical application. In this paper, starting from the practical teaching experience which we have gained over the past years, the teaching skills of introducing into the chapter, the ideas of teaching, and the difficulties and focus of teaching were detailedly described. The teaching practices have proved that the teaching method not only effectively stimulated the students' interest in learning, but also achieved the ideal teaching effect.
\end{abstract}

Keywords-Shaft; Structural Design; Machine Design; Teaching and reconsidering

\section{INTRODUCTION}

The course of Machine Design studies the design issues of mechanical devices and mechanical system, and as a foundation course of technology for machinery majors, it mainly cultivates the students' capacity in comprehensively using various mechanical parts and mechanisms as well as the knowledge of other optional courses to design mechanical driving devices and simple machines. This course involves a wide range of knowledge, and strong practicalness, and possesses an important supporting role in cultivating students' capacity in analyzing and handling actual engineering issues.

"The Structural Design of Shaft" is an important chapter of Machine Design, and in various kinds of examinations, generally, the stipulated score proportion is about $10 \%$. Meanwhile, shaft is one of the key parts for constructing machineries, and is used to support the revolving parts and transmit motion and power. What's more, all transmission parts conducting rotational motion must be installed on shaft before carrying out the motion and the transmission of power [1]. Therefore, it occupies an important position in the theory of teaching and practical application.

However, the structural design of shaft not only needs to meet lots of requirements, such as the installation, positioning, and fixation of parts on the shaft as well as the shaft manufacturing techniques; besides, since the failure mode of shaft is mainly fatigue break, the relevant fatigue theories shall also be used. The students can be nonplussed over the aforementioned issues as well as lots of design formula, charts and sizes [2]. Therefore, "The Structural Design of Shaft" is the key point and difficulty in the teaching process. In the previous research, the case teaching methodology [2], the model-aided teaching method [3], and the task-driven and informatization combined teaching method [4] have been mainly discussed. But there are few discussions about the positioning of parts on the shaft and the confirmation of shaft section size in the teaching process of Structural Design of Shaft. Thus, based on teaching experiences as well as the obvious teaching effect which teaching and research group has gained over the past years, the relevant teaching experiences are given to share with colleagues in the paper, aiming to provide certain experience reference for teaching "The Structural Design of Shaft" and similar courses.

\section{TEACHING TECHNIQUES}

\section{A. Teaching introduction techniques}

Teaching introduction is the initial link for classroom teaching, and the good introduction of classroom teaching can motivate the students' learning interests, give students the definite teaching objectives, the key points and difficulties of the course, and liven up the classroom climate to directly improve the classroom teaching quality. Thus, in the teaching process of this section, the physical model method, animation playing method and heuristic introduction method by raising question $[5,6]$ are adopted.

Before giving the lesson, it is requested to use physical model mode to show the broken shaft in the speed reducer, and use the form of video to play the phenomenon of broken shaft in actual life, such as the constantly occurred broken shaft incidents in vehicles. After completing the physical display and the animation demonstration, it is requested to put forward questions to students, including "what are the main reasons of the broken shaft? And why does the phenomenon of broken shaft often occur under the status of such advanced vehicle technologies?", so that the students can enter into the study of this chapter's contents with interests and doubts.

\section{B. Teaching thought techniques}

The teaching thought refers to the teaching process designed by teachers for the classroom teaching, and through the design of teaching thought, the classroom teaching contents can be arranged from simplicity to complexity, and from shallow to deep level to arouse the students' thirst for knowledge, so that the satisfied teaching effect $[5,6]$ can be achieved. Thus, in the teaching process of this section, the teaching thought is: the phenomenon of broken shaft $\rightarrow$ shaft fatigue break characteristics $\rightarrow$ the proposed assembly plan for parts on the shaft $\rightarrow$ the positioning of parts on the shaft $\rightarrow$ the diameter and length confirmation of various shaft sections $\rightarrow$ the common measures for improving the strength of shaft $\rightarrow$ the structure techniques of shaft $\rightarrow$ the brief summary of the chapter. In the phenomenon of broken shaft thereof, it is requested to mainly display the various phenomena of broken shaft in actual life, especially the phenomena of broken shaft of 
vehicles in combination with news, so as to arise the students' studying interests. For the part about the shaft fatigue break characteristics, firstly, it is requested to briefly introduce the contents about "the fatigue strength of mechanical parts", and then explain the shaft fatigue break characteristics in combination with Figure 1: (1) The stress subjected thereby during the fatigue break is small, which is generally lower than the yield strength of materials. (2) Generally, the fracture doesn't have obvious plastic deformation. And no matter it is the fragile material or plastic material, the form of expression is brittle fracture. Therefore, fatigue break is more sudden and dangerous. (3) Fatigue break is a process of damage accumulation, and it requests time, so the service life of parts can be calculated; (4)Fatigue fracture can be divided into two

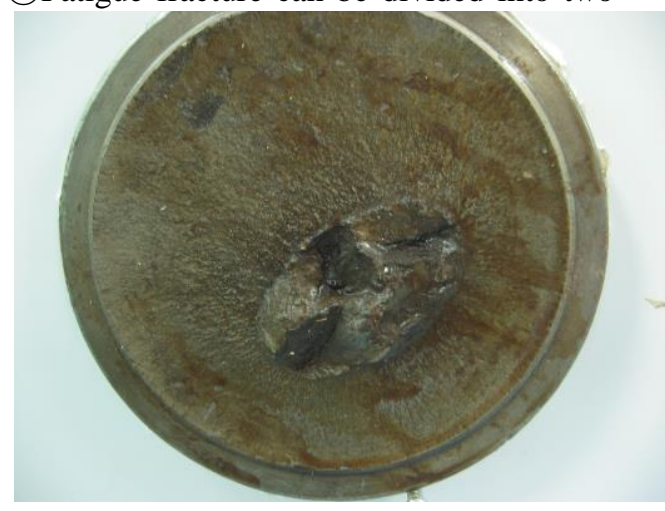

(a) Speed Reducer Shaft sections: the fatigue section and the brittle fracture section; for the fatigue section, the surface is smooth, and for the brittle fracture section, the surface is rougher. Then definitely answer that the main reason for the broken shaft is shaft fatigue, and the main reason of shaft fatigue break is the improper structural design of shaft. When explaining other contents, it is requested to provide clear drawings and then explain the assembly scheme, the positioning, size confirmation and other issues in combination with these drawings. Finally, it is requested to make a brief summary of the chapter, and meanwhile, use examples in the classroom to explain the common design errors of shaft system, and arrange relevant exercises to students as their homework.

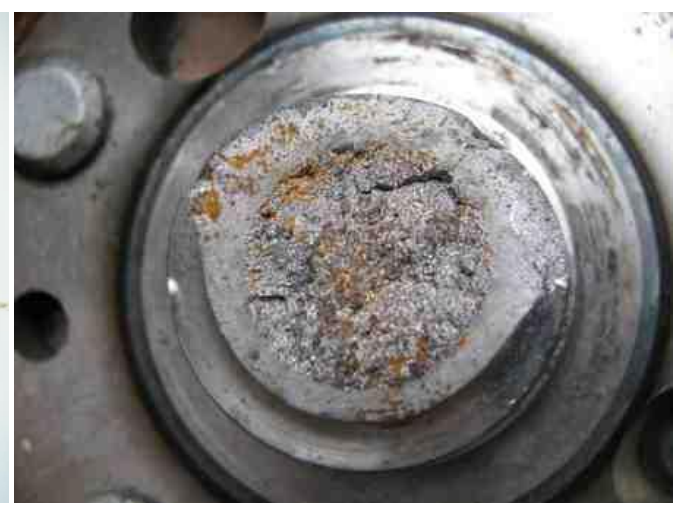

(b) Automobile Shaft

Fig. 1. The Characteristic Pattern of Shaft Fatigue Break

\section{Difficulties and key points for teaching}

As can be seen from the design contents about the homework and designs of Machine Design courses of previous students, the students cannot profoundly master the positioning of parts on the shaft and the confirmation on the size (diameter and length) of various shaft sections in the structural design of shaft, and they adopted the method of rote memorization, or completed the homework or designs through referring to design examples, and failed to flexibly master the method to confirm the size. Thus, the difficulties and key points for contents of this chapter refer to the positioning of parts on the shaft and the confirmation on the size of various shaft sections.

The positioning of parts on the shaft can be divided into two types, i.e., the shaft positioning and the circumference positioning, of which the circumference positioning mainly adopts various keys, while the shaft positioning is more complicated. The shaft positioning of parts on the shaft is realized through mainly using the shaft collar, the sleeve, shaft end ring, bearing end plate, round nut and other structures or components. To let students more profoundly know and understand various structures, in the teaching process, it is requested to explain the positioning of parts on the shaft through combing the shafts in kind and various positioning figures.

After completing the explanation of theoretical knowledge, it is requested to use the wrong structural design of shaft as the example (as shown in Figure 2), to let students point out design errors, and then make corrections. Through 2-3 error correction examples, the students can basically master the issues that shall be noted in the structural design of shaft. After completing example explanation, it is requested to guide the students to summarize the common errors in the structural design of shaft, and then obtain the conclusion that the common errors for the structural design of shaft are mainly centralized in bearing, bearing cover, key, and shaft section length. 


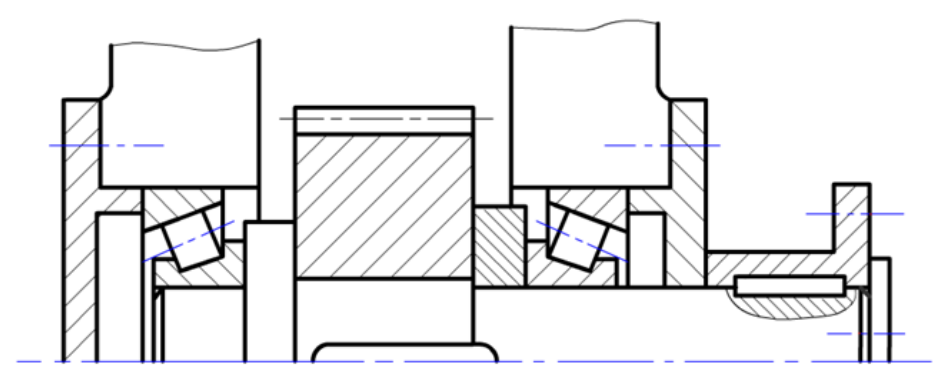

Fig. 2. Common Errors in Shaft Structural Design

The confirmation on the size (diameter and length) of various shaft sections can be specifically explained through taking Figure 3 as the example. Figure 3 (a) is the structural

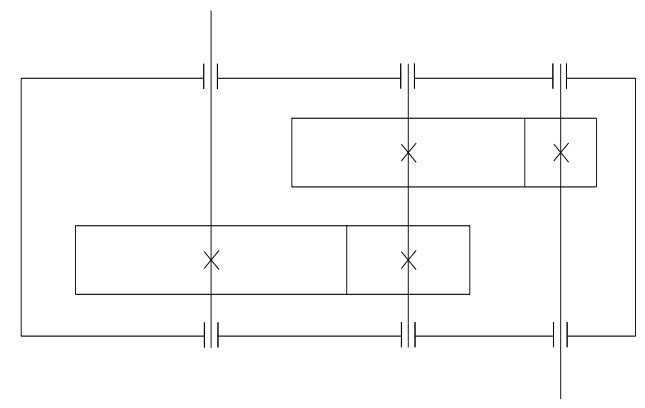

(a) Structural Schematic Diagram of Speed Reducer schematic diagram of two stage speed reducer, and (b) is the structural diagram of intermediate shaft of two stage speed reducer.

Fig. 3. Shaft Size Design

\section{1) Diameter confirmation}

Firstly, initially confirm the minimum diameter of the shaft:

$$
d_{\min }=A_{0} \sqrt[3]{P / n} \text {, and to facilitate the explanation, we }
$$

hereby assume that $d_{\min }=42.5 \mathrm{~mm}$, the width of gear installed on Shaft Section 2 is $60 \mathrm{~mm}$, and the width of gear installed on Shaft Section 4 is $80 \mathrm{~mm}$. The minimum diameter of the intermediate shaft is apparently the Shaft Section 1 and 6 installed at the bearing part, and the bearing aperture is the integral multiples of 5, so the diameter of Shaft Section 1 and 6 refers to $d_{1}=d_{6}=45 \mathrm{~mm}$ and the bearing model is initially selected as 60309; At the right of Shaft Section 1, it is requested to install sleeve to fix the gear on Shaft Section 2, so the shaft shoulder at the right of Shaft Section 1 is the nonpositioned shaft shoulder, and the non-positioned shaft shoulder height (radius difference) refers to $h=1 \sim 2 \mathrm{~mm}$, $d_{2}=d_{1}+(2 \sim 4)=47 \sim 49 \mathrm{~mm}$. As per the standard size, $d_{2}=47.5 \mathrm{~mm}$ is taken. The shaft shoulder at the right of Shaft Section 2 is the positioned shaft shoulder, and the height of the shaft shoulder refers to $h_{2}=(0.07 \sim 0.1) d_{2}=(0.07 \sim 0.1) \times 47.5=3.325 \sim 4.75 \mathrm{~mm}$, and $h=4.25 \mathrm{~mm}$ is taken, so the diameter of Shaft Section 3 refers to $d_{3}=d_{2}+2 \times 4.25=47.5+9=56 \mathrm{~mm}$; Shaft Section 4 is gear and shaft integrated, so there is no need to confirm the diameter; The rolling bearing on Shaft Section 6 adopts the right shaft shoulder for shaft positioning, and through searching the bearing manual, it can be founded that the height of the positioned shaft shoulder for 60309 bearing refers to $h=4.5 \mathrm{~mm}$, so the diameter of Shaft Section 5 refers to $d_{5}=d_{6}+2 \times 4.5=45+9=54 \mathrm{~mm}$.

\section{2) Length confirmation}

When confirming the length of three shafts, since the input shaft and output shaft merely has one additional section of connection part in length under the comparison with the intermediate shaft, and the confirmation on the length of this part is relatively simple, the shaft length shall be calculated from the intermediate shaft. The confirmation on the length of various shaft sections is hereby explained through taking the intermediate shaft as an example.

The overall length of the intermediate shaft is determined by two gears, one pair of bearings and the proper interval between parts. Provided that the distance $(\Delta)$ between the gear and the internal wall of the box is equivalent to $16 \mathrm{~mm}$, in consideration of the casting error of the box, when confirming the position of the rolling bearing, a certain distance (s) shall be kept from the internal wall of the box, and $\mathrm{s}$ is equivalent to 8mm; The width (B) of 60309 bearing is equivalent to $25 \mathrm{~mm}$ through searching the bearing manual, in consideration of the fact that the width of gear installed on Shaft Section 2 is $2 \mathrm{~mm}$ longer than the length of Shaft Section 2, so the length of Shaft Section 1 can be calculated, i.e., $l_{1}=B+\Delta+s+2=25+16+8+2=51 \mathrm{~mm}$; The length of Shaft Section 2 is $2 \mathrm{~mm}$ smaller than the width of the gear, so the length of Shaft Section 2 can be calculated, i.e., $l_{2}=60-2=58 \mathrm{~mm}$; The width of Shaft Section 3 can also be 
calculated, i.e., $l_{3} \approx 1.4 h=1.4 \times 4.25=5.95 \mathrm{~mm}$, and $6 \mathrm{~mm}$ is taken as the width of Shaft Section 3, i.e., $l_{3}=6 \mathrm{~mm}$; The length of Shaft Section 4 is the width of the bearing, so $l_{4}=60 \mathrm{~mm}$. The length of Shaft Section 5 refers to $l_{5}=\Delta+s=16+8=24 \mathrm{~mm}$. And the length of Shaft Section 6 is the same as the width of the bearing, i.e., $l_{6}=\mathrm{B}=25 \mathrm{~mm}$.

Through referring to the aforementioned steps, the structural designs of input shaft and output shaft can be completed. The confirmation on the diameters and lengths of various shaft sections can be explained through examples, and this can make the structural design of shaft more distinctive, and the students can understand them more easily.

\section{TEACHING RECONSIDERATION}

Interest is the best teacher. When to instruct this chapter, we shall display the phenomena of shaft break in real life by real shafts, figures and videos, especially the vehicle shaft breaking incidents in order to guide students to consider the reasons of shaft break and to ascertain the main reason is the improper structural design of shaft. Thus, this motivates students' learning initiative and interest.

How to arrange the teaching content, it is advised to be from simple to complex, from easy to hard in order to enhance student's confidence and to inspire student's thirst for knowledge [5-6] .

Selection and interpretation of difficult and key contents in this chapter play a critical role of student's learning quality. More contents, requirements and formulas as well as no unique design results make students feel harder when to learn this chapter. Thus, teach by cases; teach the design process of shaft structure gradually and in details especially interpret how to determine diameter and length of shaft section, so we can get a good teaching effect.

During the teaching, we also leave some time for students to understand all and raise questions after explaining the common issues in designing with living examples of the design of shaft structure. During the course brief summary, the review of difficulties and key knowledge in this chapter shall be focused on. As for the selection of exercises, moderately difficult exercises on common shafts in real life are the best, especially error correction is preferred to be added to structural design of shaft.

\section{CONCLUSION}

"The Structural Design of Shaft" is an important section in the course of Machine Design and is the necessary knowledge of the course of Machine Design as well as the basic knowledge of mechanical product development for students in future, so it occupies a significant position in the theory of teaching and practical application. From teaching in years, it is seen that students are more attracted to the course in case we can wisely design the teaching introduction combining to life practices and reasonably design teaching thoughts and effectively explain positioning of parts on the shaft and the confirmation of shaft section size. Meanwhile, teaching effect is improved by doing more with less.

\section{REFERENCES}

[1] Pu Liang-gui, Chen Guo-ding, Wu Li-yan. Machine Design Version 9 [M] 2013 Beijing: Higher Education Press.

[2] An Qi, Wang Jian-wen. Exploration on Teaching Skills of Shaft Design in the Course of Machine Design [J]. Higher Education in Chemical Engineering 2013 (04):66-70.

[3] Kang Ying, Tian Chuan Teaching Research of Autodesk Inventor Simulation Applied in the Structural Design of Shaft [J]. Modern agricultural machinery, 2015, 42(06):121,123.

[4] Sun Hua-fang .The Structural Design of Shaft: Task Driven and Information-Based Teaching Method [J] Techno-Style 2015(02):235.

[5] Zhu Dai-gen, Yang Can-yu, Wang Yuan and so on. Teaching and Reconsidering on Mechanical Self-locking Mechanism [J] Forestry Machinery \& Woodworking Equipment, 2017, 45(6):50-52.

[6] Wang Yuan, Zhong Li-hui, Wang Ying-biao and so on. Teaching and reconsidering of Calculation of Drive Ratio of Turnover Gear Wheels [J] Forestry Machinery \& Woodworking Equipment 2016, 44(12):45-48. 